\title{
Factors inducing depression as effective tool in therapy
}

\author{
Khushboo and B Sharma* \\ Department of Biochemistry, University of Allahabad, Allahabad 211002, India
}

\begin{abstract}
Depression being a psychological disorder is known to cause morbidity and mortality of the concerned individual globally. According to an estimate from the World Health Organisation (WHO), about 57 million people equivalent to about $18 \%$ of the global population are suffering from depression in India. There are several known factors responsible for inducing depression in humans such as abusing drugs and alcohol, overwork, poor diet, using excess caffeine or sugar, lack of exercise, poor sleep, sexual abuse, genetic disorders, sadness, physical health issue, brain chemistry imbalance, lack of confidence, rejection/loneliness, loss of loved one etc. According to an epidemiological data, 30 40\% of occurrences of depressive disorder involve genetic factors. Consequently, environmental factors also play significant role in development of depression. Studies have shown that cognitive therapy is as efficacious as antidepressant medications in treating depression which is believed to reduce the risk of relapse even after its discontinuation. Cognitive therapy and antidepressant medication probably engage some similar neural mechanisms, as well as mechanisms that are distinctive to each. Extensive research is therefore needed to delineate the population suffering from a specific kind of factor inducing depression which may help develop adequate therapy to treat the patients quickly and effectively.
\end{abstract}

\section{Introduction}

The level of stressors in the life of humans is ever on increase in modern era since very transition from childhood, puberty and adulthood making them susceptible to development of psychological disorders finally leading to depression [1]. The adolescents develop depression due to many factors including loss of a very close relative, unfavourable behaviour conducted by step mother or father, drug abuse and bullying or teasing etc. On the other hand, in adults the depression may crop up due to brain chemistry imbalance, genetic disorders, drugs and alcohol abuse, lack of exercise and confidence, loss of loved ones, loss of motivation overwork, poor diet, physical health issue, use of excess caffeine or sugar, poor sleep, sexual abuse, sadness, rejection/ loneliness, etc.

In Japan, psychological disorders have been included among the four major diseases such as cancer, diabetes, heart disease and stroke [2]. According to an estimate from WHO, about 300 million people are currently suffering from depression globally which counts for $4.3 \%$ of the world's population. The available reports suggest that till 2020 about $4.3 \%$ of Indian population and $10 \sim 15 \%$ of Japanese population may suffer from depression [3].

Therefore, addressing depression represents an urgent challenge. This article provides a brief overview and recent advances on different aspects of depression and possible remedial measures to treat this psychosomatic disorder in humans.

\section{Forms of depression}

There are five common forms of depression such as (1) Major depression-having symptoms of depression most of the day, nearly every day for at least 2 weeks that interfere with your ability to work, sleep, study, eat, and enjoy life. An episode can occur only once in a person's lifetime, but more often, a person has several episodes. (2) Persistent depressive disorder (dysthymia)-having symptoms of depression that last for at least 2 years. A person diagnosed with this form of depression may have episodes of major depression along with periods of less severe symptoms. Some forms of depression are slightly different, or they may develop under unique circumstances, such as. (3) Perinatal Depression: Women with perinatal depression experience full-blown major depression during pregnancy or after delivery (postpartum depression). (4) Seasonal Affective Disorder (SAD): SAD is a type of depression that comes and goes with the seasons, typically starting in the late fall and early winter and going away during the spring and summer. (5) Psychotic Depression: This type of depression occurs when a person has severe depression plus some form of psychosis, such as having disturbing false fixed beliefs (delusions) or hearing or seeing upsetting things that others cannot hear or see (hallucinations). Other examples of depressive disorders include disruptive mood dysregulation disorder (diagnosed in children and adolescents) and premenstrual dysphoric disorder. Depression can also be one phase of bipolar disorder (formerly called manic-depression). But a person with bipolar disorder also experiences extreme high-euphoric or irritable-moods called "mania" or a less severe form called "hypomania" [4]

Causes of depression: Major causes of occurrence of depression in people include the patients suffering from cancer, chronic pain, diabetes, or other such chronic diseases are increasingly likely to become depressed as disease severity increases [5-8]. Obsessive, melancholic, and other such personality types have also been associated with susceptibility to depression [9]. It may also be caused by drugs that are used in treatment of physical diseases. These therapeutic drugs are diverse and include anti-hypertensive drugs, hormone drugs, antiulcer drugs, anti-tuberculosis drugs, anti-Parkinson's disease drugs, immunomodulatory drugs, and psychotropic drugs [10].

*Correspondence to: B Sharma, Department of Biochemistry, University of Allahabad, Allahabad 211002, India, E-mail: sharmabi@yahoo.com

Key words: depression, environmental factors, cognitive therapy, antidepressants

Received: December 09, 2019; Accepted: December 17, 2019; Published: December 20, 2019 
Genetic factors associated depression: When an immediate family (parents, children, or siblings) includes a person with depression, the familial incidence is 1.5 to 3 times higher [11,12]. Research with identical twins has also shown that when one twin develops depression, the probability that the other twin will also develop depression is 25 to 93\% [13]. These reports imply that in some cases, genetic factors may play a role in the onset of depression. Studies examining postmortem brains of and, thus, they are not broken down by proteasomes. As a result, there is an overabundance of transporter, and more uptake of serotonin in the synaptic cleft. Accordingly, the amount of free serotonin is reduced. The aforementioned abnormal behaviors were attenuated by sertraline, a serotonin transporter inhibitor. Imipramine also mitigated some of the abnormal behaviours [14].

Currently, depression is diagnosed by a psychiatrist based on patient symptoms. However, approximately $80 \%$ of new patients seek consultation from a doctor of internal medicine but do not receive a proper diagnosis. If we could provide biomarkers for diagnosis of depression similar to blood glucose for that of diabetes, even a general physician could make a diagnosis. Because patients with intractable depression have diminished amounts of ubiquitinated serotonin transporter in their lymphocytes, we have applied for a patent and propose the possibility that the amount of ubiquitinated serotonin transporter may be a biomarker for depression diagnoses [15].

Lifestyle factors and environmental causes of major depression: Physical health is an important foundation of mental health. People who are not physically healthy are at an increased risk for developing depression. People who engage in unhealthy lifestyle practices also have a more difficult time overcoming depressive episodes than healthier people, as their unhealthy lifestyle practices tend to work against many treatment effects. Negative lifestyle factors that can contribute to a depressive episode or drag one out include: (1) Abusing drugs and alcohol-- The disease outcomes chosen for the current analysis were depression, panic disorder, post-traumatic stress disorder (PTSD), alcohol abuse/ dependence, drug abuse/dependence and suicide attempts. Evidence for causality came from twin studies, prospective studies and representative community studies. In particular, the three twin studies available provided strong evidence of a causal relationship as they inherently controlled for the genetic and family environment factors that are also associated with mental disorders [16-18]. These studies provide evidence of significant associations between panic disorder, alcohol abuse/dependence, drug abuse/dependence and suicide attempts and depression. (2) Poor diet, including excess caffeine or sugar- If a person is suffering from low mood, feels tense and irritable, is tired all the time, tends to comfort eat, has sleeping problems and a reduced interest in sex, and some of the above apply, the chances are they are short on serotonin. Depression as a biochemical phenomenon, best dealt with by antidepressant medication. However, there is a third aspect to the onset and treatment of depression that is given little heed: nutrition. One factor that often underlies depression is poor control of blood glucose levels. The symptoms of impaired blood sugar control are many, and include fatigue, irritability, dizziness, insomnia, excessive sweating (especially at night), poor concentration and forgetfulness, excessive thirst, depression and crying spells, digestive disturbances and blurred vision [19].

The most accepted biochemical theory explaining the root cause of aforesaid psychosomatic imbalances relies on perturbations in the metabolism of two types of neurotransmitters in brain: (1) the metabolism of serotonin which is a mood enhancer and it is synthesised using Trytophan as a precursor amino acid, and (2) the metabolism of adrenaline, dopamine and nor-adrenaline which influence motivation and are synthesised using phenylalanine as a precursor amino-acid. In cases of depression, these amino acids are given two to three times each in $100 \mathrm{mg}$ dose of 5 -HTP every time to the affected individual. Sometimes, this regimen is supplemented with different vitamins such as B12 and folic acid and minerals, which are thought to be involved in synthesis of serotonin from 5-HTP.

Other factors causing depression in any individual may include (1) Poor sleep-Sleep disturbance is one of the key symptoms of this disease, which may even act as a key factor posing risk to suicide. Therefore a deep sleep for such patients is recommended as it may help recover from depression to certain extent [20]. (2) Sexual abuse- There are evidences which indicate a close relationship between depression and sexual abuse, which is characterised as inappropriate and undesirable sexual solicitation such genital touching or fondling; or penetration in terms of oral, anal or vaginal intercourse or attempted intercourse of a child by an aged perso [21]. (3) Genetic depression and role of candidate genesAs established by meta-analysis, about 20 genes have been found to be associated with onset of depression [22]. (4) Health issues- Depression have also been shown to be emerged and linked with the physical illness of an individual as tested by a study primarily in women [2325]; though such an association between depression and physical illness may be highly nonspecific and unbiological [26]. (5) Perturbations in brain chemistry- The development of chemical imbalance in brain also contributes as a key player in depression. The perturbations in the metabolism of monoamines which act as neurotransmitters in central nervous system (CNS) may offer suitable explanations for emergence of depression. Any alterations in its complex metabolic pathway may result occurrence of subtle changes in synthesis, storage, release, and deactivation of monoamines [27]. Several workers have reported that most of the application of antidepressants helps recover such patients from mental illness by re-establishment of chemical balance in brain via enhancing the levels of monoamines [28,29]. (6) Rejection and Loneliness: Loneliness has been found to develop symptoms of depression as they lose happiness and become pessimistic [30,31]. In the patients suffering from depression due to loneliness gradually develop negative feelings and wrong judgement of personality (7). Loss of loved one: Another important cause of depression could be the unexpected loss of loved one which exerts plenty of stress on the person concerned and it may destabilise his/her mental balance and may result into psychiatric disorders [32,33]. A summary of these factors has been presented in Table 1.

\section{Additional Factors}

Environmental factors: Various environmental factors including physical or chemical have also been reported to immensely contribute in the onset of depression among the people. The anthropogenic or synthetic chemicals, such as food additives and preservatives, pesticides, hormones and drugs, and many industrial wastes become part of the environment and get mixed into air, water, soil, food item and animal/plant products. These chemical factors have been reported to cause depression after reaching into the food chain and getting accumulated into body systems. The physical environmental factors causing depression may include noise pollution, radiations, natural disasters such as destructive hurricanes, tsunamis, and earthquakes, and several other dangerous environmental events. Electrical pollution caused by radio waves produced by electrical equipments is invisible, silent, odourless, and tasteless but not fit for health. These factors may generate symptoms of depression including muscle twitches and cramps, and severe breathlessness (Figure 1). 
Table 1. A summary of different factors involved in depression

\begin{tabular}{|l|l|}
\hline Factors & Actions \\
\hline Abusing drugs and alcohol & $\begin{array}{l}\text { Panic disorder, post-traumatic stress } \\
\text { disorder (PTSD) }\end{array}$ \\
\hline Poor diet, including excess caffeine or sugar & Malnutrition mediated neurological disorders \\
\hline Poor sleep & $\begin{array}{l}\text { Reduced melatonin synthesis and mental } \\
\text { imbalance }\end{array}$ \\
\hline Sexual abuse & Psychological fears and trauma \\
\hline $\begin{array}{l}\text { Genetic depression and role of candidate } \\
\text { genes }\end{array}$ & $\begin{array}{l}\text { Over expression or low expression of } \\
\text { candidate genes causing depression }\end{array}$ \\
\hline Health issues & Disease induced depression \\
\hline Perturbations in brain chemistry & Improper brain function induced depression \\
\hline Rejection and Loneliness & Isolation induced depression \\
\hline Loss of loved one & Perturbed feelings induced depression \\
\hline Environmental factors & $\begin{array}{l}\text { Physical and chemical factors induced } \\
\text { depression }\end{array}$ \\
\hline
\end{tabular}

Table 2. A summary of different important remedies implied in depression

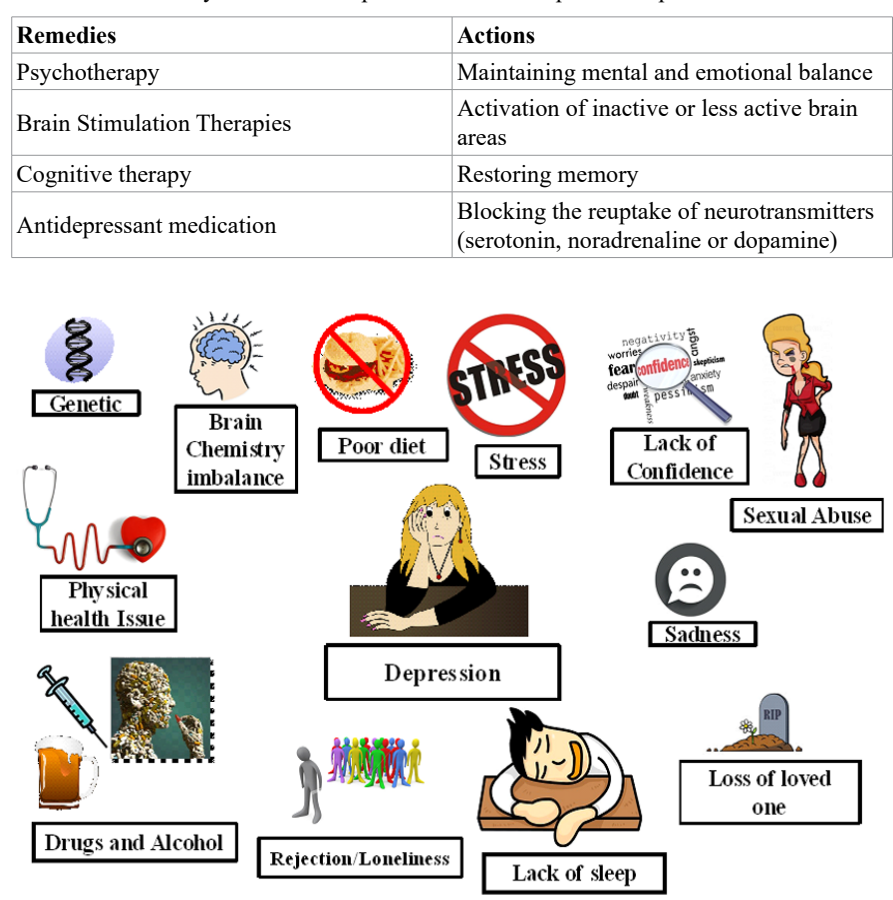

Figure 1. Scheme showing factors responsible for depression

\section{Remedial measures to combat depression}

Psychotherapy: Psychotherapy helps by teaching new ways of thinking and behaving, and changing habits that may be contributing to depression. This therapy can help understand and work through difficult relationships or situations that may be causing depression or making it worse.

Brain Stimulation Therapies: Electroconvulsive therapy (ECT) and other brain stimulation therapies may be useful to those people suffering from severe depression who do not respond to antidepressant medications. ECT is considered to be the best therapy with longest history of use.

\section{Physiological treatments}

Cognitive therapy: Cognitive therapy has been found to be the most appropriate, safe and efficacious therapy of major depressive disorder. Cognitive therapy provides protection against relapse and recurrence [34]. Cognitive therapy may help patients acquire the abilities to (i) identify the thoughts and images that accompany and precede the experience of upsetting emotions, (ii) distance themselves from these thoughts and images, (iii) validate their beliefs and (iv) identify the themes in the content of the thoughts and images that occur across a range of situations.

\section{Chemical treatments}

Antidepressant medication: The antidepressant medications include agents that block the reuptake of serotonin, noradrenaline or dopamine, the key players of the neurotransmitter systems. The selective serotonin-reuptake inhibitors (SSRIs) have been the most widely prescribed antidepressant medications to date, although the newer serotonin/noradrenaline-reuptake inhibitors (SNRIs) are also now coming into frequent use. The effectiveness of antidepressant treatment has been proved through several placebo-controlled clinical trials, though different patients respond differently to the antidepressant treatment when used in isolation or in combination of antidepressant treatment [35-37].

However, the antidepressant treatments appear to be symptomsuppressive rather than remedial [38]. It has been observed that the antidepressant treatment decreases future risk of depressive episodes once their use is terminated [39]. Research on humans and animals have indicated that antidepressant treatments may alter the regulatory processes of monoamine systems, especially the serotonin (5-HT), noradrenaline (NA) and dopamine (DA) systems. These agents have been observed to influence the neurotransmitter metabolism for example MAOIs can affect neurotransmitters degradation, the SSRIs, SNRIs, and tricyclic antidepressants (TCAs) can affect the reuptake mechanisms which can reduce appetite, emotional responses, sleep, and sexual interest in the patients suffering from depression [40,41]. A summary of these remedial measures have been presented in Table 2 .

\section{Conclusion}

In addition to the factors such as abusing drugs and alcohol, overwork, poor diet, use of excess caffeine or sugar, lack of exercise, poor sleep, sexual abuse, genetic disorders, sadness, physical health issue, brain chemistry imbalance, lack of confidence, rejection/loneliness, loss of loved one etc., several environmental factors have been found to associated to trigger depression in an individual. These factors comprise physical, chemical and biological indices. The application of physiological or chemical treatments has proved to act as effective tools towards successful remedies of patients from depression. The cognitive therapy and antidepressant medications have shown effective promises in treating depression. However, extensive research is required to delineate the population suffering from a specific factor which induces depression as it may help develop adequate therapy to treat the patients quickly and effectively.

\section{Acknowledgements}

Khushboo thanks UGC-New Delhi for providing financial assistance in the form of a Research Fellowship. Khushboo and BS gratefully acknowledge the valuable support from UGC-SAP, New Delhi and DST-FIST, New Delhi, to the Department of Biochemistry of University of Allahabad for providing facilities to carry out research.

\section{Conflicts of interests}

The authors declare that they do not have any conflicts of interests. 


\section{References}

1. Roth TL, Lubin FD, Funk AJ, Sweatt JD (2009) Lasting epigenetic influence of earlylife adversity on the BDNF gene. Biol Psychiatry 65: 760-769. [Crossref]

2. Kyodo News (2011) Mental illness is subsumed under "five major disease" by medical program policy of Ministry of Health, Labour and Welfare [Internet]. Tokyo: Kyodo News.

3. Kyodo News (2010) Ministry of Health, Labour and Welfare estimates that about 2.7 trillion yen loss is depression and suicide [Internet]. Tokyo: Kyodo News.

4. https://www.nimh.nih.gov/health/publications/depression depressionbasics-508-01112017_150043.pdf

5. Williams S, Dale J (2006) The effectiveness of treatment for depression/depressive symptoms in adults with cancer: a systematic review. Br J Cancer 94: 372-390. [Crossref]

6. Chida Y, Hamer M, Wardle J, Steptoe A (2008) Do stress-related psychosocial factors contribute to cancer incidence and survival? Nat Clin Pract Oncol 5: 466-475. [Crossref]

7. Von Korff M, Crane P, Lane M, Miglioretti DL, Simon G, et al. (2005) Chronic spinal pain and physical-mental comorbidity in the United States: results from the national comorbidity survey replication. Pain 113: 331-339. [Crossref]

8. Kessler RC, Ormel J, Demler O, Stang PE (2003) Comorbid mental disorders account for the role impairment of commonly occurring chronic physical disorders: results from the National Comorbidity Survey. J Occup Environ Med 45: 1257-1266. [Crossref]

9. Stratakis CA, Chrousos GP (1995) Neuroendocrinology and pathophysiology of the stress system. Ann N Y Acad Sci 771: 1-18. [Crossref]

10. Patten SB, Love EJ (1997) Drug-induced depression. Psychother Psychosom 66: 6373. [crossref]

11. Warner V, Weissman MM, Mufson L, Wickramaratne PJ (1999) Grandparents, parents, and grandchildren at high risk for depression: a three-generation study. $J \mathrm{Am}$ Acad Child Adolesc Psychiatry 38: 289-296. [Crossref]

12. Weissman MM, Warner V, Wickramaratne P, Moreau D, Olfson M (1997) Offspring of depressed parents. 10 Years later. Arch Gen Psychiatry 54: 932-940. [Crossref]

13. Heim C, Binder EB (2012) Current research trends in early life stress and depression: review of human studies on sensitive periods, gene-environment interactions, and epigenetics. Exp Neurol 233: 102-111. [Crossref]

14. Nabeshima T, Mouri A, inventors (2012); Meijo University, assignee. Method for determining depression, kit for analyzing serotonin transporter, and kit for analyzing ubiquitinated serotonin transporter in blood. Japanese patent JP 2012- 068348.

15. Nabeshima T, Mouri A, Noda Y (2013) inventors; Meijo University, assignee. Marker for depression, assay method, diagnostic method of depression, screening method for antidepression drugs and kit. Japanese patent JP 2013-005911.

16. Dinwiddie S, Heath AC, Dunne MP, Bucholz KK, Madden PA, et al. (2000) Early sexual abuse and lifetime psychopathology: a co-twin-control study. Psychol Med 30: 41-52. [Crossref]

17. Kendler KS, Bulik CM, Silberg J, Hettema JM, Myers J, et al. (2000) Childhood sexual abuse and adult psychiatric and substance use disorders in women: an epidemiological and cotwin control analysis. Arch Gen Psychiatry 57: 953-959. [Crossref]

18. Nelson EC, Heath AC, Madden PA, Cooper ML, Dinwiddie SH, et al. (2002) Association between selfreported childhood sexual abuse and adverse psychosocial outcomes: results from a twin study. Arch Gen Psychiatry 59:139-145. [Crossref]

19. Patrick (2003) Holford Depression: the nutrition connection Primary Care Mental Health 1: $9 \pm 16$.

20. David Nutt, DM, Sue Wilson, Louise Paterson (2008) Sleep, disorders as core symptoms of depression. Dialogues Clin Neurosci 10: 329-336. [Crossref]
21. Finkelhor D, Hotaling G, Lewis IA, Smith C (1990) Sexual abuse in a national survey of adult men and women: prevalence, characteristics, and risk factors. Child Abuse Negl 14: 19-28. [Crossref]

22. Maria Shadrina, Elena A Bondarenko, Petr A Slominsky (2018) Genetics Factors in Major Depression Disease. Front Psychiatry 9: 334. [Crossref]

23. Kendler KS, Neale M, Kessler R, Heath A, Eaves L (1993) A twin study of recent life events and difficulties. Arch Gen Psychiatry 50: 789-796. [Crossref]

24. Kendler KS, Thornton LM, Gardner CO (2001) Genetic risk, number of previous depressive episodes, and stressful life events in predicting onset of major depression. Am J Psychiatry 158: 582-156. [Crossref]

25. Kendler KS, Gardner CO, Prescott CA (2002) Toward a comprehensive developmenta model for major depression in women. Am J Psychiatry 159: 1133-1145. [Crossref]

26. Guy M Goodwin (2006) Depression and physical diseases. Dialogues Clin Neurosci 8: 259-265. [Crossref]

27. Healy D (2001) The antidepressant drama. In M. N. Weissman (Ed.), Treatment of depression: Bridging the 21st century (pp. 7-34). Washington, DC: American Psychiatric Press.

28. Masand PS, Gupta S (1999) Selective serotonin-reuptake inhibitors: An update. Harv Rev Psychiatry 7: 69-84. [Crossref]

29. Kessler RC, Berglund P, Demler O, Jin R, Koretz D, et al. (2003) The epidemiology of major depressive disorder: Results from the National Comorbidity Survey Replication (NCS-R). JAMA 289: 3095-3105. [Crossref]

30. West DA, Kellner R, Moore-West M (1986). The Effects of Loneliness: A Review of the Literature. Compr Psychiatry 27: 351-383. [Crossref]

31. Singh B, Kiran UV (2013) Loneliness among elderly women. International Journal of Humanities and Social Science Invention. 2: 10-14.

32. Raheel Mushtaq, Sheikh Shoib, Tabindah Shah, Sahil Mushtaq (2014) Relationship Between Loneliness, Psychiatric Disorders and Physical Health? A Review on the Psychological Aspects of Loneliness. J Clin and Diagn Res 8: 01-04. [Crossref]

33. Keyes KM, Pratt C, Galea S, McLaughlin AK, Koenen KC, et al. (2014) The Burden of Loss: Unexpected death of a loved one and psychiatric disorders across the life course in a national study. Am J Psychiatry 171: 864-871. [Crossref]

34. Beck AT, Rush AJ, Shaw BF, Emery G (1979) Cognitive therapy of depression. Guilford; New York.

35. Depression Guideline Panel (1993) Depression in Primary Care, Vol 2: Treatment of Major Depression (Clinical Practice Guideline No 5; AHCPR Publ No 93-0551). U.S. Department of Health and HumanServices, Public Health Service, Agency for Health Care Policy and Research; Rockville, MD.

36. Agency for Health Care Policy and Research (1999) Treatment of depression - newer pharmacotherapies:Summary, evidence report/technology assessment number 7 . Rockville, MD: US Department of Health and Human Services.

37. Thase ME, Rush AJ (1997) When at first you don't succeed...sequential strategies for antidepressant nonresponders. J Clin Psychiatry 58: 23-29. [Crossref]

38. Hollon SD, Thase ME, Markowitz JC (2002) Treatment and Prevention of Depression. Psychol Sci Public Interest 3: 39-77. [Crossref]

39. American Psychiatric Association (2000) Practice guideline for the treatment of patients with major depressive disorder (revision). Am J Psychiatry 157: 1-45.

40. Sheline YI, Barch DM, Donnelly JM, Ollinger JM, Snyder AZ, et al (2001). Increased amygdala response to masked emotional faces in depressed subjects resolves with antidepressant treatment: an fMRI study. Biol Psychiatry 50: 651-658. [Crossref]

41. Khushboo, Sharma B (2017) Antidepressants: mechanism of action, toxicity and possible amelioration. $J$ Appl Biotech \& Bioeng 3: 437-448.

Copyright: ( 2019 Khushboo and Sharma B. This is an open-access article distributed under the terms of the Creative Commons Attribution License, which permits unrestricted use, distribution, and reproduction in any medium, provided the original author and source are credited. 